Jul 1st, 12:00 AM

\title{
Concepts of Decision Support for River Rehabilitation
}

Peter Reichert

M.E. Borsuk

M. Hostmann

S. Schweizer

C. Spörri

See next page for additional authors

Follow this and additional works at: https://scholarsarchive.byu.edu/iemssconference

Reichert, Peter; Borsuk, M. E.; Hostmann, M.; Schweizer, S.; Spörri, C.; Tockner, K.; and Truffer, Bernhard, "Concepts of Decision Support for River Rehabilitation" (2004). International Congress on Environmental Modelling and Software. 84.

https://scholarsarchive.byu.edu/iemssconference/2004/all/84

This Event is brought to you for free and open access by the Civil and Environmental Engineering at BYU ScholarsArchive. It has been accepted for inclusion in International Congress on Environmental Modelling and Software by an authorized administrator of BYU ScholarsArchive. For more information, please contact scholarsarchive@byu.edu, ellen_amatangelo@byu.edu. 
Presenter/Author Information

Peter Reichert, M. E. Borsuk, M. Hostmann, S. Schweizer, C. Spörri, K. Tockner, and Bernhard Truffer 


\title{
Concepts of Decision Support for River Rehabilitation
}

\author{
P. Reichert, M. Borsuk, M. Hostmann, S. Schweizer, C. Spörri, K. Tockner and B. Truffer \\ Swiss Federal Institute for Environmental Science and Technology (EAWAG) \\ 8600 Dübendorf, Switzerland
}

\begin{abstract}
River rehabilitation decisions, like other decisions in environmental management, are often taken by authorities without sufficient transparency about how different goals, outcomes, and concerns were considered during the decision making process. This can lead to lack of acceptance or even opposition by stakeholders. In this paper, a concept is outlined for the use of techniques of decision analysis to structure scientist and stakeholder involvement in river rehabilitation decisions. The main elements of this structure are (i) an objectives hierarchy that facilitates explicit discussion of goals, (ii) an integrative probability network model for the prediction of the consequences of rehabilitation alternatives, and (iii) a mathematical representation of preferences for possible outcomes elicited from important stakeholders. This structure leads to transparency about expectations of outcomes by scientists and valuations of these outcomes by stakeholders and can be used (i) to analyse synergies and conflict potential between stakeholders, (ii) to analyse the sensitivity of alternative-rankings to uncertainty in prediction and valuation, and (iii) as a basis for communicating the reasons for the decision. These analyses can be expected to stimulate the creation of alternatives with a greater degree of consensus among stakeholders. The paper concentrates on the overall concept, the objectives hierarchy and the design of the integrative model. More details about the integrative model, the stakeholder involvement process, and the assessment of results will be published separately. Because many decisions in environmental management are characterized by a complex scientific problem and diverse stakeholders, the outlined methodology will be easily transferable to other settings.
\end{abstract}

Keywords: decision analysis; stakeholder involvement; river rehabilitation.

\section{INTRODUCTION}

In many industrialized countries, river ecosystems have been strongly impacted over the past centuries, mainly by constraining their widths to gain agricultural land and improve flood protection of cultivated and urban land. River rehabilitation has the goal to reestablish part of these ecosystems. Decisions about measures of river rehabilitation are difficult because of the uncertainty about the outcomes, the number of stakeholders with partly conflicting objectives, and the difficult and time consuming governmental decision procedure.

Decision analysis techniques [von Winterfeldt and Edwards, 1986; Clemen, 1996; Eisenführ und Weber, 2003] were originally developed to support individual decision makers. However, because these techniques are used to structure the decision problem and to make explicit expectations about outcomes and preferences, they can also be used to support group decisions or to structure stakeholder involvement and communication about reasons for decisions. The potential of these and other multiple criteria decision support methods is of interest for environmental decision making [Lahdelma et al, 2000].

In this paper, we describe a general procedure of how decision analysis techniques can beneficially be used to support river rehabilitation decisions. The procedure is divided into seven steps:

1. definition of the decision problem;

2. identification of objectives and attributes;

3. identification and pre-selection of alternatives;

4. prediction of outcomes;

5. quantification of preferences of stakeholders for outcomes;

6. ranking of alternatives;

7. assessment of results.

These seven steps are briefly described in sections 1-7 of this manuscript in the context of decisions about river rehabilitation measures for a particular river reach. The problem of integrative planning of river rehabilitation in the context of the whole river basin is not addressed in this paper. 


\section{DEFINITION OF THE DECISION PROBLEM}

Definition of the decision problem consists of identification of ecological deficits of the river reach and of stakeholders involved in or affected by the decision [Hostmann et al., 2004].

\section{OBJECTIVES AND ATTRIBUTES}

\subsection{Objectives}

An objective is something a decision maker (or stakeholder) would like to achieve. Objectives can be divided into fundamental objectives (directly related to what a decision maker would like to achieve) and means objectives (lead to the accomplishment of fundamental objectives). Fundamental objectives are usually structured hierarchically according to their degree of concreteness [Clemen, 1996; Eisenführ and Weber, 2003]. The objectives at each level of such a hierarchy should be mutually exclusive and collectively exhaustive [Keeney, 1992].

Figure 1 provides a hierarchy of fundamental objectives for a rehabilitated river reach which can serve as a guideline for value assessments in river rehabilitation projects. This hierarchy was developed by scientist involved in the multidisciplinary Rhone-Thur project for scientific support of river rehabilitation projects in Switzerland [Peter et al. 2004]. It served as a basis for the value assessments by all stakeholder groups (there was no request for additional objectives when using a simplified version of this hierarchy for value assessments).

At the first level, the overall objective is divided into the objectives of achieving landscape integrity and socio-economic well-being.

Landscape integrity is further divided into ecosystem integrity and hydrogeomorphic integrity. It is obvious that, due to the important influence of river hydrology and morphology on the development of the ecosystem, we run into difficulty distinguishing means objectives from fundamental objectives and with having mutually exclusive objectives in this branch of the objectives hierarchy. Alternatives would be to either concentrate on ecosystem integrity and treat hydrogeomorphic integrity as a means objective to achieve ecosystem integrity, or to concentrate on hydrogeomorphic integrity and assume that this is sufficient to guarantee ecosystem integrity. Neither of these approaches is satisfying. The first does not account for achieving hydrogeomorphic integrity as a fundamental objective, while the second omits ecosystem integrity as an important (or even the most important) fundamental objective. This does not imply that hydrogeomorphic attributes are not useful for quanti- fying the means objective of achieving ecosystem integrity. To account for the difficulties outlined above, we decided to use both ecosystem integrity and hydrogeomorphic integrity as fundamental objectives. The difficulty of this approach is that, when characterizing the preference structure, we have to assign values to hydrogeomorphic integrity excluding its benefits to ecosystem integrity, to keep the objectives mutually exclusive (otherwise we would double-count the value of ecosystem integrity).

Ecosystem integrity is divided into natural ecosystem function and natural species diversity. At this level we again have problems of specifying mutually exclusive objectives as the species are a determinant of ecosystem function. Still, it seems necessary to distinguish between a function provided by a small number of species or by a diverse ecosystem.

Hydrogeomorphic integrity is divided into natural river morphology, natural discharge regime, and good water quality.

The branch socio-economic well-being is divided into ensuring ecosystem services, low implementation cost, and guaranteeing job opportunities. The objective of ensuring ecosystem services guarantees that society benefits from the ecosystem. Low implementation cost helps the society affording implementation of the measures. Guaranteeing job opportunities, particularly in agriculture, is an important objective of stakeholders.

Further details are represented by the lower level objectives in Figure 1.

\subsection{Attributes}

An attribute is a measurable quantity that can be used to quantify the degree of fulfilment of an objective. The lowest level objectives of the hierarchy are characterized by the attributes listed at the right-hand side of Figure 1. In some cases, these attributes can easily be used to quantify the degree of fulfilment of the corresponding objective. However, in other cases, the chosen attributes are a compromise between a good characterisation of the objective and a reasonable expected prediction accuracy.

\section{ALTERNATIVES}

Important options for rehabilitation of river sections are widening the river bed, lowering the floodplains, and construction of retention basins or side channels. Decision alternatives typically consist of combinations of these measures. In many cases, loosening river width constraints is the most important measure for rehabilitation. 


\section{PREDICTION OF OUTCOMES}

The outcomes of rehabilitation measures are difficult to predict. As rehabilitation measures usually directly affect the shape of the river bed, the most direct consequences consist of hydraulic and morphological changes. These then have consequences on the benthic population, fish, vegetation, and shoreline community. In addition, they have social and economic consequences. These relationships are visualized in Fig. 2.

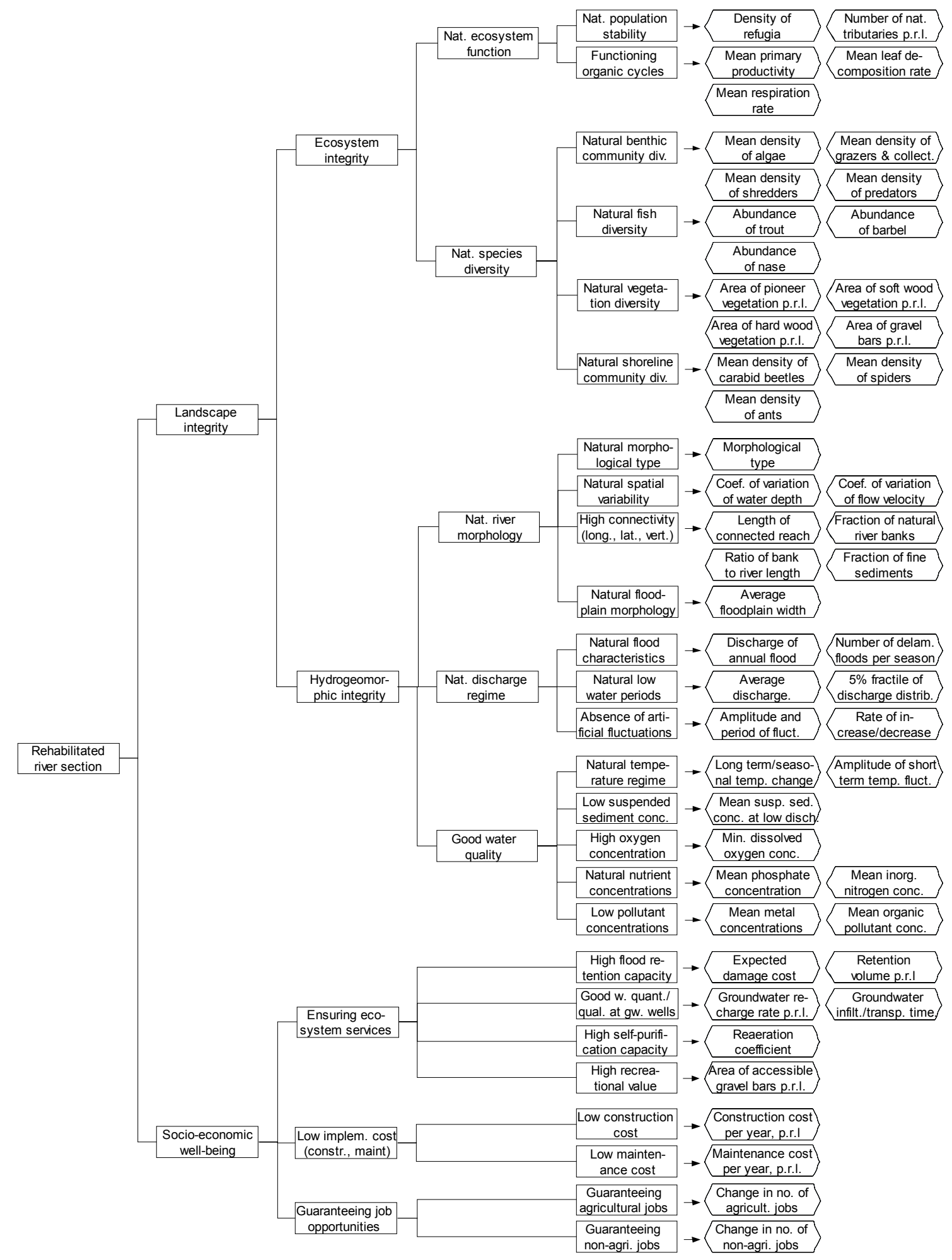

Figure 1. Objectives hierarchy (rectangular boxes and lines) and attributes (rhombic boxes) corresponding to the lowest-level objectives for a rehabilitated river section (p.r.l. = per unit river length). 


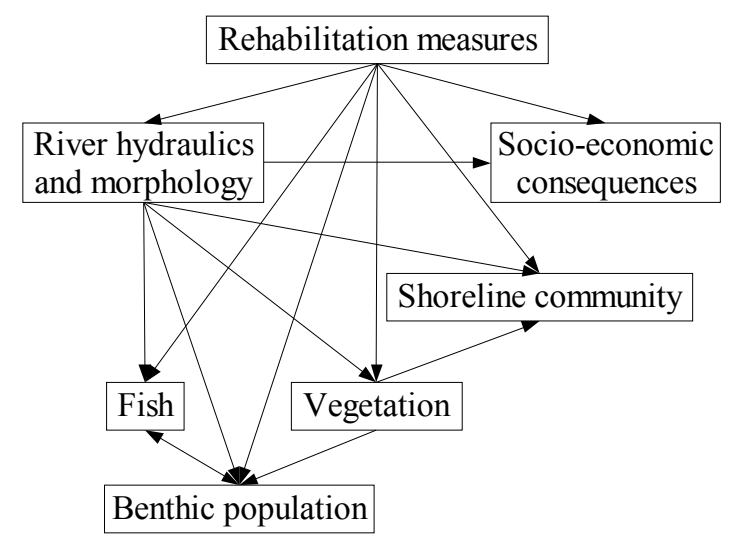

Figure 2. Important relationships between conesquences of river rehabilitation measures.

Prediction of consequences of rehabilitation measures requires a model of cause-effect relationships. Such a model must combine knowledge from all available sources such as basic scientific knowledge, specialized literature, more detailed models, measured data, and expert knowledge. Probability network models provide a very useful model structure to combine different types of knowledge, to divide a model into more easily tractable sub-models, and to explicitly consider prediction uncertainty [Pearl, 1988; Charniak, 1991; Reckhow, 1999; Borsuk et al., 2004]. This is the reason why we recommend building the integrative model of cause-effect relationships as a probability network model. Fig. 3 visualizes the most important cause-effect relationships between external forcings and all attributes identified in Fig. 1 and how those relationships are divided into the six sub-models of hydraulics, benthic population, fish, vegetation, shoreline community, and economics. Brief descriptions of how these six sub-models are constructed are given in the following six subsections. More detailed descriptions of all sub-models will be published separately.

\subsection{Hydraulic Sub-Model}

The hydraulics sub-model predicts river morphology, gravel transport, velocity and depth distribution, and river bed clogging [Schweizer et al., 2004]. It is based on an analysis of natural channel morphology predicted by one of the relationships derived by Bledsoe and Watson [2001] and considers width constraints with the aid of da Silva's [1991] analyses. Prediction of velocity distributions are based on Lamouroux [1995], and of river bed clogging on Schälchli [1993].

\subsection{Benthic Population Sub-Model}

The benthic population sub-model consists of a simplified approach relative to dynamic river benthos models [McIntire, 1973; Rutherford, 1999]. It estimates seasonal benthic population densities based on the most important influence factors affected by rehabilitation measures.

\subsection{Fish Sub-Model}

In the fish sub-model, the dependence of the parameters of a fish population model on external influence factors is formulated, and then the fish population model is solved dynamically. The results are summarized by a probability network [Lee and Rieman, 1997; Borsuk et al., 2002].

\subsection{Vegetation Sub-Model}

The vegetation model maps the response surface of a mechanistic individual-based floodplain vegetation model [Prentice et al., 1993] using a probability network.

\subsection{Terrestrial Shoreline Fauna Sub-Model}

This sub-model is based on a simple quantification of the empirical relationship between environmental driving variables and population density and species identity of carabid beetles, spiders, and ants [Boscaini et al., 2000].

\subsection{Economic Sub-Model}

The economic sub-model quantifies the effects of the revitalisation work on the local economy, and uses changes in the number of jobs as a proxy. It is built as an input-output model [Miller and Blair, 1985] that is integrated into the probability network model formalism. This type of model uses an input-output table between different sectors of the economy to derive technical coefficients through division by the sectoral outputs. It then assumes that these technical coefficients do not change and calculates the change in sectoral activities and employment for the demand change in the construction and other involved sectors during implementation of the rehabilitation measures. The underlying input-output table is constructed by adapting the national input-output table based on local employment statistics (location quotient method, Isard et al. [1998]).

\subsection{Integrative Model}

The complete model combining all sub-models can be used for decision support among alternatives. For detailed planning of river construction required for implementing the chosen alternative, more detailed investigations may be necessary.

\section{PREFERENCES FOR OUTCOMES}

Stakeholder preferences can be elicited in the form of value functions [von Winterfeldt and Edwards, 1986; Eisenführ und Weber, 2003] as functions of the attributes. Often, such multiattribute value functions will be built as weighted sums of single-attribute value functions. To keep the value elicitation tractable, the objectives hierarchy may have to be simplified. 


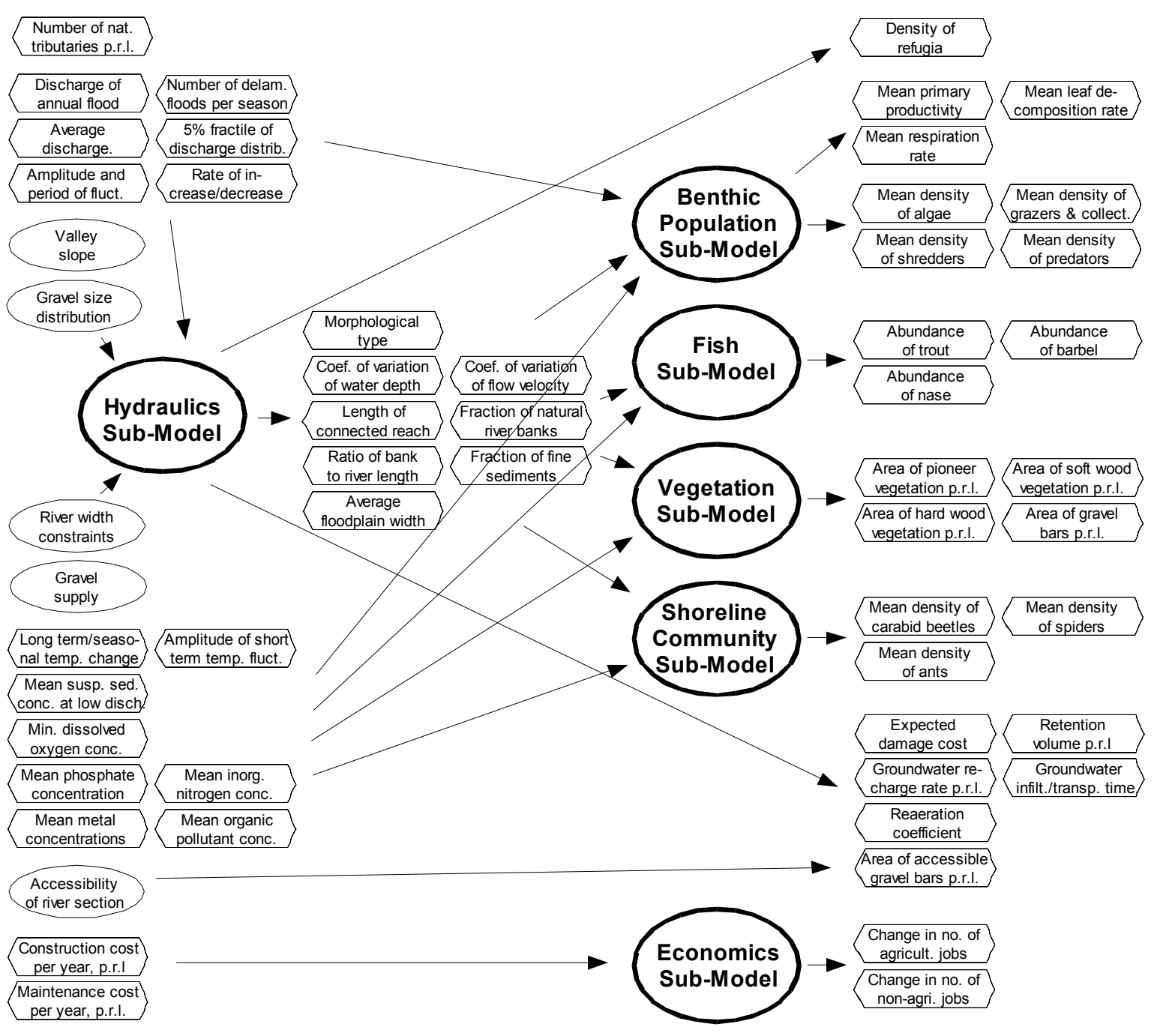

Figure 3. Integrative model for the prediction of outcomes of decision alternatives for river rehabilitation. The rhombic nodes represent the attributes shown in Fig. 1, the round nodes are additional required inputs, and the bold round nodes are the sub-models of the integrative river rehabilitation model. Nodes in the left column represent model inputs (some of them influenced by the decision alternative), nodes in the central column intermediate nodes, and nodes in the right column model outputs.

As the landscape integrity branch is resolved to a relatively high resolution in the hierarchy shown in Fig. 1, an option is to summarize ecological integrity and hydrogeomorphic integrity by a semiquantitative attribute scale visualized by a picture [Hostmann et al., 2004]. An alternative would be to elicit value functions for ecological and hydrogeomorphic attributes from scientists and let the stakeholders only assess the weights of these branches based on a description of the range of possible outcomes.

\section{RANKING OF ALTERNATIVES}

The integrative model developed in section 4 leads to predictive probability distributions of the attributes. Applying the value functions elicited in section 5 to these attributes leads to a probability distribution of preference rankings of the alternatives for each stakeholder. Figure 4 summarizes the results of such a ranking based on preliminary outcome predictions for a case study in Switzerland.

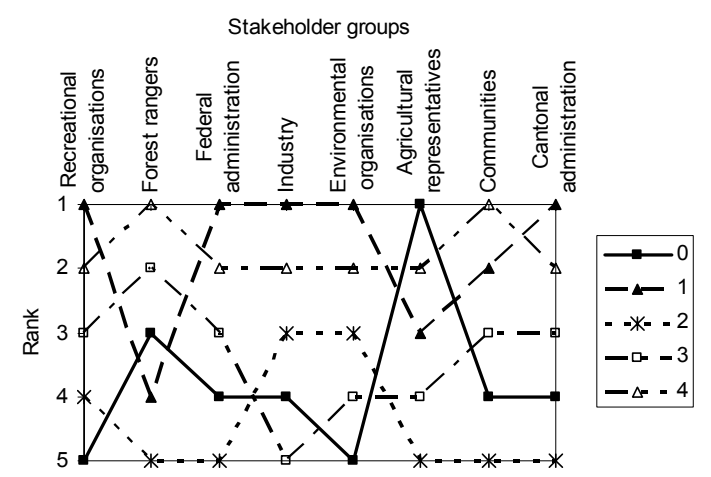

Figure 4. Example of rankings of five river rehabilitation decision alternatives for different stakeholder groups according to Hostmann et al. (2004). 


\section{ASSESSMENT OF RESULTS}

The preference rankings of the alternatives derived from predictions and value assessments can be used to evaluate acceptance and conflict potential between stakeholders (alternative 4 in Fig. 4 was developed as a compromise alternative based on the results for alternatives 0-3). This can be used to structure stakeholder discussions, to develop compromise alternatives, and to make the basis for decisions transparent [Hostmann et al., 2004]. Furthermore, the sensitivity of the results to uncertainty in prediction and valuation can be assessed.

\section{CONCLUSIONS}

River rehabilitation decisions can be controversial due to uncertain outcomes and conflicting interests of stakeholders. This paper demonstrates how decision analysis techniques can support such decisions by structuring the decision and stakeholder involvement processes and by making scientific assumptions and social preferences explicit. Nevertheless there are cases in which application of these techniques have been found to be poorly accepted [Hobbs et al., 1992]. Implementation aspects may responsible for these results.

\section{ACKNOWLEDGEMENTS}

This project was supported by the multidisciplinary Rhone-Thur project for scientific support of river rehabilitation projects in Switzerland initiated and funded by the Swiss Federal Office for Water and Geology (BWG), the Swiss Federal Institute for Environmental Science and Technology (EAWAG) and the Swiss Federal Institute for Forest, Snow and Landscape Research (WSL) [Peter et al., 2004]. In addition, many project partners contributed through stimulating discussions, comments, and suggestions to this paper.

\section{REFERENCES}

Bledsoe, B.P. and Watson, C.C., Logistic analyis of channel pattern thresholds: meandering, braiding, and incising, Geomorphology 38:281-300, 2001.

Borsuk, M.E., P. Reichert, and P. Burkhardt-Holm, A Bayesian network for investigating the decline in fish catch in Switzerland. In A.E. Rizzoli and A.J. Jakeman (Editors) Integrated Assessment and Decision Support, Proc. of the iEMSs conference, Lugano, Switzerland. Vol. 2, pp. 108-113, 2002.

Borsuk, M.E., Stow, C.A., and Reckhow, K.H. Bayesian network of eutrophication models for synthesis, prediction, and uncertainty analysis. Ecological Modelling. In press, 2004.

Boscaini, A., Franceschini,A. and Maiolini, B., River ecotones: carabid beetles as a tool for quality assessment, Hydrobiologia 422/423, 173-181, 2000.

Charniak, E., Bayesian networks without tears, AI Magazine, 12(4), 50-63, 1991.
Clemen, R.T., Making Hard Decisions, PWS-Kent, Boston, second edition, 1996.

Da Silva A.M.A.F., Alternate bars and related alluvial processes. Thesis of Master of Science, Queen's University, Kingston, Ontario, Canada, 1991.

Eisenführ, F. and Weber, M., Rationales Entscheiden, Springer, Berlin, 4th edition, 2003.

Hobbs, B.F., Chankong, V. And Hamadeh, W., Does choice of multicriteria method matter? An experiment in water resources planning, Wat. Resourc. Res. 28(7), 1767-1779, 1992.

Hostmann, M., Truffer, B., Reichert, P. and Borsuk, M.E., Stakeholder values in decision support for river rehabilitation, submitted to Archiv für Hydrobiologie, Large River Supplement, 2004.

Isard, W. et al., eds. Methods of Interregional and Regional Analysis. Ashgate, 1998.

Keeney, R.L., Value-Focused Thinking, Harvard University Press, Cambridge, 1992.

Lahdelma, R., Salminen, P. and Hokkanen, J., Using multicriteria methods in environmental planning and management, Env. Man. 26(6), 595-605, 2000.

Lamouroux, N., Souchon, Y. and Herouin, E., Predicting velocity frequency distributions in stream reaches, Wat. Resourc. Res. 31(9), 2367-2375, 1995.

Lee, D.C. and Rieman, B.E., Population viability assessment of Salmonids by using probabilistic networks, North American J. of Fisheries Management 17, 1144-1157, 1997.

McIntire, C.D., Algal dynamics in laboratory streams: a simulation model and its implications, Ecological Monographs 43, 399-420, 1973.

Miller, R.E. and Blair, P.E., Input-Output Analysis: Foundations and Extensions, Prentice-Hall, 1985.

Pearl, J., Probabilistic reasoning in intelligent systems: networks of plausible inference, Morgan Kaufmann, San Mateo, California, 1988.

Peter, A., Kienast, F. and Nutter, S., The Rhone-Thur River project: a comprehensive river rehabilitation project in Switzerland, submitted.

Prentice, I.C., Sykes, M.T. and Cramer, W., A simulation model for the transient effects of climate change on forest landscapes, Ecological Modelling 65(1-2), 51-70, 1993.

Reckhow, K.H., Water quality predictions and probability network models, Can. J. Fish. Aquat. Sci. 56, 1150-1158, 1999.

Rutherford, J.C., Scarsbrook, M.R. and Broekhuizen, N., Grazer control of stream algae: modeling temperature and flood effects, Journal of Environmental Engineering 126(4), 331-339, 1999.

Schälchli U.: Die Kolmation von Fliessgewässersohlen: Prozesse und Berechnungsgrundlagen, Mitteilungen der Versuchsanstalt für Wasserbau, Hydrologie und Glaziologie der ETH Zürich Nr. 124, 1993.

Schweizer, S., Borsuk, M.E. and Reichert, P., Predicting the hydraulic and morphological consequences of river rehabilitation, submitted to iEMSs 2004.

Von Winterfeldt, D. and Edwards, W., Decision Analysis and Behavioural Research, Cambridge University Press, 1986. 